\title{
Beyond Hofstede and GLOBE: Improving the quality of cross-cultural research
}

\author{
Rosalie L Tung ${ }^{1}$ and \\ Alain Verbeke ${ }^{2}$ \\ ${ }^{1}$ Faculty of Business Administration, Simon \\ Fraser University, Canada; ${ }^{2}$ Strategy and \\ Global Management Area, University of \\ Calgary, Canada
}

\section{Area Editors}

Correspondence:

Rosalie L Tung, Faculty of Business Administration, Simon Fraser University, 8888 University Drive, Burnaby, BC, Canada V5A 156

Tel: +17787823083

Fax: +17787824920

E-mail: tung@sfu.ca

Journal of International Business Studies (2010) 41, 1259- 1274. doi: I0. I057/jibs.20 I0.41

\section{OVERVIEW OF 41.8: HOFSTEDE AND GLOBE IN CROSS-CULTURAL RESEARCH}

While Hofstede's work was not the first systematic study on crossnational cultures, his seminal book, Culture's Consequences: International Differences in Work-Related Values (1980), succeeded in putting cross-cultural analysis at the forefront of international business (IB) research. In a later paper, he boldly asserted that the "business of international business is culture" (1994: 1). Despite the criticisms that have been voiced against his work (see McSweeney, 2002; Oyserman, Coon, \& Kemmelmeier, 2002), Hofstede's influence on the fields of IB and management is undeniable: according to Harzing's "Publish or Perish" citation index, as of June 2010 there were over 54,000 citations to his work. This is a remarkable record that attests to, first, the growing popularity of cross-cultural research in light of continued internationalization of the world economy, and second, Hofstede's personal impact on scholarly research.

This JIBS issue brings together 10 articles on culture and IB, all of which were submitted to the editorial team led by JIBS Editorin-Chief Lorraine Eden. While the articles were independently submitted through the regular double-blind reviewing process, the decision to join them in one collection creates, in effect, a Special Issue on "Culture in International Business Research", which the JIBS editors hope will be widely read and cited by IB scholars. In general terms, the papers in this collection fall into one of two categories: (1) articles and commentaries about conceptual and methodological issues associated with Hofstede's oeuvre vs the Global Leadership and Organizational Behavior Effectiveness (GLOBE) project's cultural dimensions, and (2) articles and perspectives that use culture and/or cultural dimensions, as well as the operational measurement thereof, to explain differences in behavior and practices across countries. The common feature of all these scholarly pieces is that they challenge particular assumptions often made too easily in conventional cross-cultural research.

The first paper in this collection is a perspective written by Franke and Richey that cautions against "questionable generalizations from small numbers of countries in international business research". Using statistical analysis to support their assertion, Franke and Richey argue that in order to draw "credible" generalizations in IB, a minimum of 7-10 countries must be used. This is an important message: researchers should never formulate strong conclusions about the impact of cultural dimensions on 
managerial choice or economic performance based on samples that include only one or a few countries. Even when considering only the research published between 2006 and 2009, the authors found that 53\% of the empirical studies published in JIBS, AMJ, SMJ, $M I R$ or JWB that focused on multi-country comparisons included fewer than 10 countries. Fortuitously, all empirical papers in this issue of JIBS meet the large country number criterion.

The second paper in this issue, by Venaik and Brewer, uses statistical analysis to explain the conflicting empirical findings with regard to the effects of uncertainty avoidance (UA). The authors demonstrate that the UA dimension in Hofstede's work and the GLOBE project, in fact, represent different aspects of the same construct. More specifically, Hofstede's UA version is shown to represent societal stress, whereas GLOBE's version reflects more the extent to which societies are "rule oriented". The authors recommend that researchers' decision to use either Hofstede's or GLOBE's version of UA should therefore depend on "their focal construct of interest".

These first two empirical pieces are followed by a set of four fascinating commentaries. Through detailed analysis of the questionnaire items used in the GLOBE project, Brewer and Venaik challenge the assertion made by Maseland and van Hoorn in their 2009 JIBS paper that the significant negative correlations between the "practices" and "values" in the GLOBE project can be explained in terms of the theory of diminishing marginal utility. This debate on the contributions of the GLOBE project, especially on the methodological and conceptual issues associated with the findings of negative correlations between "values" and "practices" in the GLOBE dimensions, is ongoing (see Peterson's (2004) insightful review of House, Hanges, Javidan, Dorfman, \& Gupta (2004)). The first commentary is followed by Maseland and van Hoorn's rebuttal to Brewer and Venaik's claim, where the authors reassert their original explanation. Next, Taras, Steel, and Kirkman jump into the debate between Brewer and Venaik, on the one hand, and Maseland and van Hoorn, on the other, by proffering a variety of alternative explanations (based largely on concepts from psychology and sociology) for these negative correlations. Their article is followed by a commentary from Hofstede, the doyen of crosscultural research, who summarizes his personal perspective on the debate and reiterates the question he posed in his earlier 2006 JIBS piece (Hofstede, 2006), namely "What did GLOBE really measure?"
These four commentaries as a set demonstrate the deep division among cross-cultural researchers as to what constitutes culture (that is, its key dimensions), how culture should be measured, and what culture implies for managerial practice. This debate is important because, unless researchers pay attention to these issues and differing opinions, many will and often do adopt a particular approach to defining cultural dimensions and measuring differences in these dimensions across cultures, without understanding fully the implications and possible limitations thereof.

Four empirical papers follow this debate surrounding what constitutes appropriate cultural distance dimensions and cultural distance measures. Cultural distance dimensions refer to national/ societal values on which nations or societies tend to differ, as identified in major works, such as Schwartz' value survey (1994), Inglehart and Associates' World Values Survey (www.worldvalue survey.org; Inglehart, 1997) and Trompenaars and Hampden-Turner (1997), in addition to Hofstede's cultural characteristics and the GLOBE project. Cultural distance measures refer to operational parameters that can be used as proxies for these dimensions and allow estimating scores (albeit in an imperfect fashion) to gauge the extent to which countries differ on cultural dimensions. Such measures can take the form of compound indices that bundle distance scores for individual cultural dimensions, for example, operational instruments such as the Kogut-Singh (K-S) and other indices.

Each of the four empirical papers in this JIBS issue utilizes cultural distance dimensions and measures to explain variations in managerial behavior and practices across countries. First, based on a sample of 40 nations, Stephan and Uhlaner used selective data from the GLOBE and Global Entrepreneurship Monitor to explain differences in the entrepreneurship rates across countries. Importantly, they do not just use the GLOBE dimensions, but they compute second-order factors to eliminate multicollinearity among the nine GLOBE dimensions. As a result, they can distinguish between "performance based cultures" and "socially supportive cultures", and they use this distinction to demonstrate, inter alia, that the latter (rather than the former) are conducive to higher entrepreneurship rates. Since entrepreneurship rates in society can change dramatically over time as a result of demographic, institutional and economic changes, two questions should be raised. First, are the cultural norms measured in the GLOBE project 
stable themselves? Second, is the relationship found between socially supportive societies and entrepreneurship rates likely to hold in the longer run?

Second, building upon a sample of Finnish firms, Sarala and Vaara examine the impact of both crossnational (GLOBE dimensions) and organizationallevel cultural parameters on knowledge transfer in international mergers and acquisitions (M\&As). The fascinating outcome is the positive relationship found between national cultural dimensions and international knowledge transfers, whereas no association was found between organizational level cultural differences and knowledge transfers. Sarala and Vaara demonstrate that cultural distance measures based on the K-S formula but utilizing scores from the GLOBE dimensions can be beneficial, and that higher distance should not be considered merely a cost. The paper also suggests that, at the organizational level, M\&As can affect culture through convergence (reduction of cultural differences between organizations) and crossvergence (creation of a new organizational culture). In other words, even in the short run, organizational cultures and differences in these cultures can change dramatically. Their results suggest that research should not focus solely on extant differences but also explore processes of cultural integration that could facilitate knowledge transfers. The authors also highlight the need to be informed on the various motives for M\&As in order to be able to distinguish among (1) cases where the initial corporate cultures are best left alone vs (2) cases where (one-sided) convergence should be sought vs (3) other cases where crossvergence (through mutual adjustment) is likely to be optimal, see also Verbeke (2010).

The next paper, by Shao, Kwok and Guedhami, utilizes cultural distance dimensions derived from an equally credible alternative to the Hofstede and GLOBE measures: Schwartz's (1994) values surveys. The authors focus on two of his parameters, namely Conservatism (the extent to which individuals in a society value harmony within a group, as reflected in the importance attached to family security, self-discipline and public image) and Mastery (a dimension which focuses on independence and success), to investigate the relationship between national culture and dividend policy. Using data from 21 countries that represent 27,462 data points, Shao et al. find a positive relationship between Conservatism and dividend payouts and a negative association between Mastery and such payouts. The impressive element in this paper is the masterful selection of the two specific Schwartz dimensions, as a result of thoughtful conceptual analysis driven by both theory (especially agency theory and work on information asymmetries) and insight into managerial practice.

The last paper in this issue, by Kang and Kim, examines the factors that affect governance activities of foreign acquirers. Based on a sample of foreign acquisitions in the United States over a 20-year time period, the study finds that acquirers from culturally similar countries, relative to those from culturally distant ones, are more likely to engage in "post-acquisition governance activities", mainly because they face lower information asymmetries that allow them to engage in more effective governance intervention. Here again the great strength of the paper is the thoughtful selection of relevant cultural distance dimensions and the recognition that related distance measures are likely to affect the managerial practices being studied. The distance dimensions and measures included in the paper are geographic distance, home-country language other than English, prior acquisition experience in the host country, cultural distance and a specific institutional distance parameter (differences in shareholders' rights).

Collectively, these 10 papers shed new light on some of the latest debates pertaining to the merits and limitations associated with the Hofstede vis-àvis GLOBE cultural dimensions, and they show empirically how cross-national differences in culture can affect a wide variety of IB studies: entrepreneurship, knowledge transfers, dividend policy and corporate governance. While acknowledging the intellectual contributions of these papers to, first, new insights on cultural distance dimensions and measures, and second, the similarities and/or differences between cultural phenomena in a multi-nation setting, it is pertinent and important to ask ourselves a question on the future of cross-cultural research: Where should we go from here, after gaining a better understanding of key conceptual and methodological issues surrounding the cultural dimensions in Hofstede's work and the GLOBE project on the one hand, and after having experienced the state-of-the-art in empirical work on cultural distance measures on the other hand? In other words, how can we take the field of cross-cultural research forward? Or, to put it differently, how do we progress beyond the point of adding only marginal value to extant knowledge? 


\section{CHALLENGING 10 COMMON ASSUMPTIONS ON CULTURAL DISTANCE DIMENSIONS AND MEASURES IN APPLIED IB RESEARCH}

In an earlier JIBS perspective piece, Leung, Bhagat, Buchan, Erez, and Gibson (2005) proposed to look at culture in its full complexity, as a multi-level, multi-layer construct and also strongly advocated the use of experimental methods. The multiple levels refer to the presence of distinct cultural elements at the global, national, organizational, group and individual levels. Gelfand, Nishii, and Raver (2006: 1239) echoed this call by asserting that "an exclusive focus on cultural values is insufficient to capture this complexity". We agree with Leung et al.'s (2005) and Gelfand et al.'s (2006) assessment. At the same time, we are also cognizant of the fact that most applied IB and management studies that include a culture component, and the managerial challenges that inspired these studies, are necessarily relatively narrow in scope. Here, special attention should be devoted to the quality of the empirical research (usually based on statistical analysis of secondary data and survey data, or case studies) conducted within this narrow scope, especially in terms of what cultural distance dimensions and cultural distance measures between countries may mean for strategic managerial choice and performance outcomes in international settings.

A useful starting point to improve the quality of cross-cultural studies is to highlight and challenge 10 common assumptions characteristic of much applied empirical work on cultural distance dimensions and measures, thereby revisiting and augmenting Shenkar's (2001) seminal analysis (see Table 1). While Shenkar's analysis focused explicitly on cultural distance measures, especially the K-S index, by and large, these assumptions are also relevant to broader applied work that takes on board cultural distance dimensions and measures. The 10 assumptions often affect the intrinsic quality and managerial relevance of the empirical work undertaken, thus undermining the credibility of cross-cultural studies. Many of these weaknesses are addressed appropriately in the empirical papers included in this JIBS Special Issue, but unfortunately this cannot be said about all manuscripts submitted to this journal, nor about many articles published elsewhere in credible IB and management outlets.

Our point here is not to criticize earlier research or researchers, but rather to encourage IB scholars to implement best practices in their work on culture and IB. The standards for rigor in the social sciences are continually rising; what are acceptable practices today can very quickly become unacceptable as scholars better understand the problems and develop better methods for identifying and correcting them in their work. JIBS, with its long history of publishing leading scholarship on culture and IB, should be at the forefront in this area, setting the benchmark for social science research.

\section{Assumptions 1 and 2: Generic Limitations of Applied Cultural Distance Research}

All IB and management scholars engaged in applied, cross-cultural research should be attentive to the first two assumptions in Table 1, symmetry in scores for distance measures between countries and stability of cultural distance dimensions and scores for distance measures over time, and be aware that these assumptions usually do not hold. In many cases, these two assumptions may not affect directly the quality of the empirical analysis conducted, but caution is still required when distance symmetry and stability are simply

Table 1 Ten common assumptions on cultural distance dimensions and measures in applied IB and management research

Type I: Generic limitations

1. Symmetry in scores for distance measures between countries

2. Stability of cultural distance dimensions/scores for distance measures over time

Type II: Remediable weaknesses in empirical research design

3. Linear relationship between scores for distance measures and selected dependent variables

4. Unambiguous causal linkage between cultural distance dimensions/scores and managerial choice

5. Unambiguous causal linkage between cultural distance dimensions/scores and performance outcomes

6. Equivalence between cultural distance and psychic distance

Type III: Weaknesses requiring re-conceptualization

7. Mask 1. Homogenous impact of cultural distance dimensions/scores irrespective of intra-country spatial variation

8. Mask 2. Systematically negative impact of cultural distance dimensions/scores

9. Mask 3. Homogenous impact of (national) cultural distance dimensions/scores, irrespective of firm characteristics

10. Mask 4. Appropriateness of aggregating individual (cultural) distance dimensions/scores in indices

Source: Adapted from Shenkar (2001). 
assumed. ${ }^{1}$ The first assumption, namely that of symmetry between (1) the distance perceived by country A economic actors vis-à-vis country B and (2) the distance perceived by country B economic actors vis-à-vis country $\mathrm{A}$, is often not warranted (O'Grady \& Lane, 1996). For example, Selmer, Chiu, and Shenkar (2007) found that it was much easier for 38 German expatriates to adjust comfortably in the United States than for 25 American expatriates in Germany, suggesting a substantial asymmetry in distance experienced by the two countries' actors. In many empirical settings, the assumption of symmetry is not particularly critical, for example, when assessing entry mode choices of firms from a specific country in various foreign environments. However, it is then still important to specify that any empirically established relationship is unidirectional. Any suggestion that the same relationship would hold in the opposite direction should be avoided, especially if no robustness checks are performed. Including a larger number of countries in empirical studies, and conducting long-run programs of research studying the same managerial phenomenon in multiple directions (e.g., in terms of the choice of home and host countries when studying entry mode decisions), can go a long way towards alleviating this generic research challenge.

The second assumption is that of absence of change in cultural distance dimensions across nations, and therefore of stability of scores used in cultural distance measures between countries, over time. This assumption is obviously also unrealistic (Fang, 2005-2006; Leung et al., 2005; Ralston, Egri, Stewart, Terpstra, \& Yu, 1999). The key question from an IB research perspective is whether particular changes in cultural distance dimensions, and therefore cultural distance measures between countries over time, are likely to affect in a substantive fashion managerial choice and economic performance. In longitudinal studies covering extended periods of time, careful reflection on the issue is warranted, especially if older proxies are used for operationalizing and measuring cultural distance dimensions. This may be an issue in studies where distance proxies are used as the prime explanatory elements in statistical models rather than as moderating or mediating variables.

As one example of the relevance of recognizing changes in cultural distance over time, Heuer, Cummings, and Hutabarat (1999) directly measured Hofstede's individualism/collectivism and power distance dimensions through surveys of managers in Indonesia. The authors found a narrowing over time of the differences between Indonesian and American managers for these two cultural characteristics, thus suggesting cultural crossvergence (Ralston, 2008). Furthermore, drawing upon dialectical thinking and the yin-yang principle, Fang (2005-2006: 77) used the "ocean" metaphor to explain the "(1) paradoxical nature of culture, (2) the 'moment' of culture, and (3) the new identity of national cultures in the era of globalization". The "ocean" metaphor refers to the reality that at any given time, some cultural values in a country may lie dormant until they are re-ignited by external events, such as foreign direct investment (FDI) and rapid internationalization. For example, risk taking and the entrepreneurial spirit, strong characteristics among overseas Chinese, were dampened in China at the height of communism but quickly unleashed when that country opened its door to foreign trade. In their study of Sino-Western business negotiations over a 30-year time frame, Tung, Worm, and Fang (2008) found that the "ocean" metaphor could capture more adequately the dynamic changes and complexities in present-day Chinese society than standardized, stable scores supposedly measuring China's main cultural dimensions.

In most cases, it may be beyond the scope of individual research projects to actually measure the evolution over time of the adopted cultural dimensions, but it is nevertheless imperative to recognize explicitly the reality thereof. It does not suffice to state that a particular, older measurement of cultural dimensions is probably still appropriate because other scholars use this measurement too, or because it likely changes only slowly over time, without any credible evidence that this is actually the case.

\section{Assumptions 3-6: Necessary Improvements in Empirical Research Design}

As regards the third to sixth assumptions in Table 1, substantial progress has been made to address these in contemporary research. In our view, this is often an issue of appropriate empirical modeling. Indeed, the third assumption in many IB studies has been that of a linear association between cultural distance scores, as measured by specific distance proxies on the one hand, and the selected dependent variables, on the other, meaning that any change in cultural distance scores between countries is expected to be associated with a similar change, in terms of sign and magnitude, of the 
phenomenon studied. For example, if the score for a particular cultural distance measure (supposedly capturing an underlying distance dimension) increases, the likelihood of multinational enterprise (MNE) managers choosing a joint venture rather than a wholly owned subsidiary (or vice versa), should also change proportionally. Fortunately, many recent studies published in the major management journals have adopted more sophisticated empirical approaches allowing for a variety of statistical relationships (other than linear ones) to describe the possible association between cultural distance scores and a variety of managerial choices and performance parameters, thereby taking on board a broad spectrum of moderators (Tihanyi, Griffith, \& Russell, 2005).

The fourth and fifth assumptions represent the alleged, unambiguous association (in the sense of a clear causal linkage) between cultural distance scores, on the one hand, and managerial choice or economic performance, on the other. The typical approach is one whereby a higher cultural distance score for one or several cultural distance measures is supposed to lead to additional costs, thereby shifting in an identifiable way what managers, firms and - through aggregation - even countries do. There are a number of problems here. First, any empirical study design should include only those cultural distance dimensions, and the measures associated with them, that can really be expected to affect ex ante managerial choice (such as location choice or entry mode selection) and/or ex post behavior and performance. The inclusion of particular cultural distance dimensions and related measures should therefore be carefully tailored to the empirical question at hand. Here, one should also remember that assuming causality between cultural distance scores, on the one hand, and managerial choice, on the other, in fact contradicts the possibility of a causal linkage between cultural variables and performance. In the former case, managers are assumed to make "correct" decisions ex ante. In the latter case, ex post performance differences result from "incorrect" ex ante decisions, safe cases of unexpected external events that could not reasonably have been predicted.

Second, most dependent variables in IB do not exist in a vacuum. For example, what is the relevance of assessing the impact of cultural distance scores on trade patterns at the macrolevel, if other entry modes such as FDI are ignored? An increase in cultural distance scores might actually lead to an increase in trade volumes, if exports replace production abroad (and FDI), because differences in the underlying cultural dimensions make it particularly difficult to manage production operations (at least as compared with international trading activities). In other words, if FDI stocks and flows are kept out of the analysis, little can be concluded.

Third, there is a clear endogeneity problem here: IB transactions do not occur primarily because of cultural distance scores (and thus differences in the underlying cultural dimensions) or the lack thereof. These transactions occur because firms command bundles of firm-specific advantages (FSAs) that can be best exploited or augmented through combination with resources found elsewhere (Hennart, 2009; Rugman, 1981; Verbeke, 2009). In other words, no direct, generalizable linkage (divorced from a specific situational context) should be expected between cultural distance scores and managerial choice or economic performance (Tihanyi et al., 2005).

The problem is somewhat similar to the one found in the largely misconceived empirical literature assessing the link between multinationality and performance (Hennart, 2007; Verbeke \& Brugman, 2009; Verbeke, Li, and Goerzen, 2009). In that literature, multinationality is assumed to have a direct effect on performance, but in real life most often does not, or at least not in a truly significant way, simply because any observed level of multinationality results from managerial decisions on resource deployment and recombination in ways that benefit the firm more than alternative deployments and recombinations.

Similarly, the absence of genuine causality between cultural distance scores (and variations in the underlying cultural dimensions) and firm performance holds for firms making particular location decisions that lead to operations in a portfolio of host countries with particular distance scores vis-à-vis the home country; these are endogenous choices at least partly based on each firm's extant resource reservoir. Unfortunately, the majority of empirical papers that build upon secondary data and assess either the impact of multinationality on performance or the impact of culture on managerial choice and performance seldom bother to check through interviews with managers or case studies as to whether or not their statistical results are consistent with managerial reality or represent mainly statistical noise (Barkema, Bell, \& Pennings, 1996). However, this is ultimately a manageable challenge related to the proper design 
of empirical work and the honest interpretation of its outcomes.

The sixth assumption reflects the expected equivalence between cultural distance and psychic distance. Psychic distance, which is actually unrelated to any psychological characteristics of particular individuals, can be traced back to Beckerman's (1956) economics paper on trade patterns and refers to the "subjectively perceived distance to a foreign country" (Håkanson \& Ambos, 2010: 2). Earlier on, we made a distinction between cultural distance dimensions and cultural distance measures, with the latter leading to specific scores and compound indices supposedly describing the distance between two nations. Unfortunately, these dimensions and measures do not fully capture psychic distance, which is really the key parameter affecting many managerial choices in an IB context. In Beckerman's work, other factors than "objective" economic parameters (for example, familiarity resulting from personal relationships) appeared to influence trade patterns, an insight marvelously translated to micro-level decision making by the Uppsala School's internationalization studies (Johanson and Vahlne, 2009). In the oeuvre of the Uppsala school scholars, cultural distance dimensions and related measures represent only one component of psychic distance (other components being related, inter alia, to a variety of information barriers). If many individuals in a country share a particular level of psychic distance vis-à-vis a foreign nation, this may become a predictor of managerial choice and perhaps even economic performance. (The latter will occur only if ex ante perceptions of distance were consistent with reality, but mistakes were made in acting upon these, or if ex ante perceptions did not adequately represent economic, cultural, institutional, etc. realities in the first place.)

Psychic distance is often wrongly equated with cultural distance in empirical work, although it is a much broader concept that includes many other sources of distance than culture related ones. Håkanson and Ambos (2010) analyzed 148 empirical studies using the K-S index, an operational tool based on Hofstede's cultural distance dimensions. ${ }^{2}$ In $40 \%$ of the studies, this index was actually used as the proxy for psychic distance in an ex ante decision-making context (e.g., instrumental to investment location selection or entry mode choice). In the remaining $60 \%$, scholars utilized the index in an ex post context, allegedly reflecting the ease/difficulty of doing business in a foreign country, and affecting performance (e.g., subsidiary and joint venture performance, human resources management practices) (Håkanson \& Ambos, 2010).

The problem is thus that a concept solely related to expected challenges of operating in a culturally unfamiliar environment (i.e., a compound index of cultural distance scores intended to measure differences in underlying cultural dimensions between countries) is wrongly equated with the much broader and more encompassing concept of psychic distance (Dow, 2000; Dow \& Karunaratna, 2006). As one example of the relevance of distinguishing between these two concepts, Dow and Larimo's (2008) work suggests that the K-S (1988) index misses $75 \%$ of the predictive power of psychic distance's full effect on entry mode selection, with other key psychic distance components including differences between countries in language, religion, industrial development, education and degree of democracy. A positive element for future research is that scales are now available that actually allow measuring differences across countries (see, e.g., Dow \& Karunaratna, 2006). In addition, several databases are readily available that facilitate the consideration of cultural variations across countries, beyond Hofstede and the GLOBE project. These include Schwartz's value survey, Inglehart and associates' World Values Survey (www.world valuesurvey.org), and the Trompenaars HampdenTurner ecological (cross-cultural) database (www .thtconsulting.com).

\section{Assumptions 7-10: The Four Masks of Focused Cross-Cultural Studies}

The last four assumptions (7-10) represent, in our view, more serious challenges to applied IB and management research in a cross-cultural setting. These assumptions create a clearly inaccurate crosscultural context within which actual managerial choices are allegedly made and subsequent economic performance is achieved. In other words, if the actual measurements of the cultural dimensions selected by IB and management researchers in their applied work are inappropriate in a microlevel context (irrespective of their quality as averages that are more representative at the macro or national level of analysis), the relevance of these dimensions toward explaining phenomena pertaining to management becomes debatable at best. At the same time, these challenges are not necessarily easy to address through actionable changes in empirical study design. Rejecting these 
assumptions, which are the equivalent of four masks behind which many cross-cultural studies attempt to hide in order to disguise their intrinsic weaknesses, amounts to substantive reconceptualization as to the meaning and potential value added of cross-cultural studies.

Mask 1. The seventh assumption is that of spatial homogeneity within a single nation. It may make sense to assume spatial homogeneity and estimate average national scores for underlying cultural dimensions when attempting to explain macrolevel phenomena. However, at the micro-level, when trying to establish linkages between scores for cultural dimensions and managerial choices or economic performance levels, due consideration should be given to intra-national differences. Drawing upon the concepts of polycontextualization (Von Glinow, Shapiro, \& Brett, 2004), culture as a multi-level, multi-layer construct (Gelfand et al., 2006; Leung et al., 2005), and the multicultural status of most nation-states (Naylor, 1996), Tung (2008a) has called for the need to balance cross-national and intra-national diversity in cross-cultural research.

Growing intra-national diversity in many countries has highlighted the problems, both conceptual and methodological, associated with assuming cultural homogeneity among people within a given nation-state. Intra-national diversity has been brought about, in part at least, by the globalization of the workforce. "Global workforce 2000 " refers to the rising incidence of migration of people across international boundaries (Johnston, 1991), caused first by the boundaryless careers generated by the increasing willingness of people to live and work in other countries (Stahl, Miller, \& Tung, 2002; Tung, 1998), and second, by the "brain circulation" that stems from immigrants' desire to return to their countries of origin to partake in economic development and/or establish dual beachheads of businesses in both their countries of origin and countries of residency (Saxenian, 2002; Tung, 2007).

The most popular cross-national dimensions used in IB research to date, such as Hofstede's (1980), GLOBE's (House et al., 2004), Trompenaars and Hampden-Turner's (1997), Inglehart and associates' World Values Survey (Inglehart, 1997), and Schwartz' (1994) values survey, are all premised on the assumption of cultural homogeneity within a given country. As Tung (2008a: 45) warned, the "fallacious assumption" of cultural uniformity can "risk the generation of results that mask or confound the phenomena under investigation".

There is growing evidence to show that intranational diversity (i.e., variations within a country) can be as salient as, and sometimes more so than, differences across countries. Tung and Baumann (2009) compared the attitudes toward money, material possessions and savings among samples of Caucasian Canadians, Chinese Canadians, Caucasian Australians, Chinese Australians and Chinese from China. The authors found that there were more similarities between ethnic Chinese in Canada and Australia with Chinese in China, on the one hand, vis-à-vis their Caucasian counterparts in Canada and Australia, on the other. This observation may have significant implications for IB research. For example, it may imply that firms owned and managed by individuals from a foreign ethnicity may select as their target market in a host country, individuals or firms with the same ethnic background. Ethnicity might thus represent an FSA, especially for emerging market firms (Miller, Thomas, Eden, \& Hitt, 2008). This finding lends credence to Fletcher and Fang's (2006: 435) strong statement that a source of "weakness in cross-cultural comparisons is the tendency in the literature to make comparisons between countries rather than ethnic groups ... (when) globalization and the borderless economy are making nation states increasingly irrelevant".

In some ways, understanding intra-national diversity can be more nebulous and challenging when compared with deciphering cross-national distance in cultural dimensions because so many variables - such as ethnicity, age, gender, generational differences (for example, first generation Chinese Canadians vis-à-vis second and third generation Chinese Canadians), religion and so on - can come into play in affecting the values, behaviors and practices of peoples within a given nation state. In fact, it may be more difficult to gauge the impact of these demographic variables and their interaction effects than taking the country scores from Hofstede or the GLOBE index on a given country. There are widely available cultural distance indices (such as K-S's, see also the discussion of the tenth assumption below) that researchers can readily use.

In contrast, there is no short-cut approach to gauge the almost endless possibility of variations within a given nation-state that can arise from the diversity of background of its peoples. In line with the "ocean" metaphor (Fang, 2005-2006), it is 
important to realize that a country's score on the measure for a given cultural dimension is, at best, a one-time snapshot of the characteristics of a select segment of a given nation; therefore, it would be woefully inadequate and misleading to interpret the rest of the country's behavior and tendencies based on a generalized index. Whereas such snapshots may still be useful as average scores for a nation in macro-level studies, they should not be blindly adopted in micro-level studies. Hopefully, the growing recognition that significant differences can exist within peoples in a given nation-state will hasten this move toward the understanding of culture as a multi-level, multi-layered construct showing substantial variation within a single country (Gelfand et al., 2006; Leung et al., 2005; Miller et al., 2008). In addition, we should also recognize that the extent of intra-national diversity can vary significantly from one country to the next, with each country characterized by a particular degree of "cultural tightness-looseness" (Gelfand et al., 2006: 1226-1227). The latter is intended to gauge "how clear and pervasive norms are within societies, ... and how much tolerance there is for deviance from norms". This concept of cultural tightness-looseness holds promise as it can complement existing measures of cultural dimensions, not merely adding to the current inventory of cultural distance parameters.

Moreover, the growing incidence of "brain circulation" has given rise to a new cultural subgroup, which Tung (2008a) has labeled as ex-host country nationals (EHCNs). EHCNs from emerging markets, such as China and India, have been lured to return to their respective countries of origin to partake in the fruits of development that have transformed their former home countries. The 2008 financial crisis that hit the industrialized countries very hard has accelerated this trend. Furthermore, because of the growth opportunities in these emerging markets, many MNEs are expanding their operations in these regions. A common assumption among many MNEs is that the best people to head and/or manage their operations in emerging markets are EHCNs. Thus, studies that seek to examine the interactions between expatriates and hostcountry nationals, but which continue to assume that EHCNs share the home or investor country's culture, can yield misleading findings. As Tung (2008b: 471) asserted, the phenomenon of brain circulation "has challenged us to fundamentally rethink the parameters and the way in which we have conducted cross-cultural research in the past".
The key point to remember from the analysis above is that in micro-level studies, only in-depth insight into the idiosyncratic nature of firms' locational characteristics in home and host environments, and the characteristics of senior MNE managers, expatriates, etc. in the firms studied can yield relevant associations between culture-related variables, on the one hand, and managerial choice or economic performance variables, on the other. Take this mask of intra-country homogeneity away, and the credibility of more than one cross-cultural study may become seriously undermined.

Mask 2. The eighth assumption is that cultural distance dimensions/scores systematically engender negative outcomes. This assumption needs to be carefully reconsidered, particularly when conceptualizing micro-level studies. In fact, if adopted by researchers in applied work and conveyed to practitioners, it can trigger wrong managerial choices or negatively affect performance as a selffulfilling prophecy (Brown, Rugman, \& Verbeke, 1988). To date, most research questions and hypotheses in IB and management publications on cross-national interactions, including foreign market entry strategies, have been guided by the concepts of homophily and psychic distance (see also the discussion above on Assumption 6). Homophily, in essence, means that people prefer to be with those who resemble themselves (Ibarra, 1993; Lazarsfeld \& Merton, 1954). This explains, in line with past research, why in general, expatriates from the United States are more comfortable with assignments to Canada and the United Kingdom (culturally similar countries) as opposed to China, Japan and Korea (culturally distant countries) (Tung, 1998), and why superiors should take into consideration the level of cultural novelty (i.e., the difference between the cultures of the home and host countries) when assessing expatriates' performance abroad (Selmer, Chiu, \& Shenkar, 2007).

The psychic distance concept discussed above (from a perspective of appropriate empirical design, see the discussion of Assumption 6), is analogous to that of homophily and, as noted, is a fundamental tenet of the Johanson and Vahlne $(1977,2009)$ and broader Uppsala School theories of incrementalism in entering foreign markets. These theories suggest that internationally operating firms first seek to enter markets that are psychically closer to that of the home country, before venturing into psychically distant locations after they have gained more IB experience. In fairness to Johanson and Vahlne's 
analysis, their expectation was that psychic distance would decline with the absolute level of economic development of the target country: regardless of proximity, wealthier countries were expected to have a better developed infrastructure for the collection, analysis and dissemination of information relevant to operating in the market. Nevertheless, the assumption that psychic distance does help explain a firm's evolutionary path toward internationalization parallels the principle of homophily, which asserts that relationships and associations tend to be formed among peoples from similar backgrounds (i.e., that are psychically closer). ${ }^{3}$

While the principles of homophily and psychic distance may hold in the West, even in micro-level studies, the findings by Mamman (1995) and Carr, Rugimbana, Walkom and Bolitho (2001) in their studies of sub-Saharan Africa and Tanzania suggest the opposite. In their studies, they found that hostcountry nationals were more likely to hold negative stereotypes about expatriates from other developing countries, particularly those from neighboring nations. Borrowing the principle of inverse resonance in applied mechanics, Carr et al. (2001) have used this concept to explain the more positive or neutral reception by host nationals of individuals from culturally distant countries.

The inverse resonance hypothesis is diametrically opposed to the homophily hypothesis advocated in the mainstream IB and management literature. Even though the studies on inverse resonance have, thus far, been done on Africa only, we suspect that this principle will most probably hold in Asia as well. For example, it would be erroneous to assume that it is best to send a Hong Kong or Taiwanese Chinese to manage in China or a Sri Lankan or Pakistani to manage in India. ${ }^{4}$ Here, the critical issue in applied research is not to find a statistical curve that would best describe the association between cultural (or psychic) distance scores and managerial choice or performance outcomes. The real challenge is to understand at the macro- and micro-levels, on the basis of direct observation, what distance means in practice, and why highdistance solutions (e.g., in the context of expatriates) may sometimes be preferred over low distance ones, and may even lead to superior performance. Here, one should also take into account that sources of distance other than culture (e.g., differences in economic development level) may help explain the attractiveness of a high-distance solution (e.g., when associated with a higher likelihood of advanced knowledge transfers). It is intuitively appealing to wear the mask of homophily, but this mask does disguise substantial cross-cultural complexity that more often than not remains unaccounted for.

Mask 3. The ninth assumption is the homogenous impact of (national) cultural distance, irrespective of firm characteristics. It does make sense to assess in applied macro- and meso-level studies how distance, as measured by average distance scores for underlying, relevant cultural dimensions, affects location choices, sequences in location choices, entry mode choices, managerial practices and ultimately economic performance. However, the question then arises as to how this translates into any managerial prescription in micro-level IB studies. That MNEs command idiosyncratic resource bundles and successful strategy either results from emulating rival firms' strategies but in a superior fashion, or from making very different choices as to resource deployment.

In this context, there are five weaknesses associated with neglecting firm-level characteristics when assessing the impacts of cultural distance dimensions/measures in applied micro-level studies. First, the firm may command resources alleviating any problems that could transpire in an allegedly high-distance context at the macrolevel. For example, a US-based company contemplating expansion to Taiwan might not experience any distance-related difficulties associated with such a location choice if the MNE employs senior managers who were born and raised in Taiwan, and kept their local networks active, even after completing graduate studies in the United States and working for American companies (this situation is similar to the use of EHCNs, discussed under Assumption 7). In more general terms, the costs of negotiating with local partners, transferring knowledge to a Taiwanese production operation, and developing the required location-bound FSAs to be fully productive there, may be quite low because of the idiosyncratic resources the firm commands.

Second, international experience can go a long way to alleviating distance challenges in IB (Hutzschenreuter \& Voll, 2008; Hutzschenreuter et al., 2010). More specifically, what matters in the case of a new entry is not so much the distance between the home country A and the host country $\mathrm{B}$, but between the newly entered host country B and the host country C, where the firm already has substantial experience and that shows the lowest 
distance to the newly entered country B. Ideally, one should even recognize the importance of intra-country variation in the context of added cultural distance, as suggested when discussing Assumption 7.

The issue of added cultural distance is important, as it suggests that much of the extant, applied IB and management research at the micro-level, building upon differences between home and host countries, has been fundamentally ill-conceived, especially in an era of network MNEs where host-country operations can be strategic leaders and even command subsidiary-specific advantages (Rugman \& Verbeke, 2001). In this context, it is especially important to investigate the diversity in the educational, functional and geographic experience of the senior management team. Tung and Chung (2010), for example, found that Australian firms that were owned by immigrants from China, Hong Kong and Taiwan were more likely to enter their respective former countries of residence via joint or wholly owned ventures as compared to exporting and licensing by other Australian firms without such connections.

Third, the impact of distance may be very different depending upon the value chain activity involved. For example, Rugman and Verbeke (2004, 2005,2008 ) have shown in the context of regional vs global strategies of the Fortune Global 500 companies, that input markets appear to be much less prone to suffer from costs of distance than output markets, because resource commitments by the firm at the output side are usually more one-sided than at the input side.

Fourth, in accordance with our analysis above (see the discussion around Assumption 8), viewing distance as a cost and as a barrier to IB may make perfect sense for firms merely interested in exploiting their extant FSAs in new settings with the lowest possible requirements for adaptation. However, distance may actually confer benefits to firms interested primarily in developing new FSAs in host environments, for example, in the context of strategic asset seeking investments; although the net benefits of penetrating highdistance environments should never be taken for granted and overestimated (Verbeke \& Kenworthy, 2008).

Fifth, much past micro-level research has attempted to describe the impact of cultural distance dimensions/scores on strategic choices such as entry mode selection (e.g., wholly owned subsidiary vs joint venture vs exports). However, what is sometimes forgotten is that internalization implies replacing external distance (i.e., dealing with host country, arm's length parties) by internal distance (i.e., working with host-country employees). It is again the idiosyncratic resource bundles, including the firm's operating routines and its capacity to train and acculturate foreign employees, which will determine the option that should be selected based on its net benefits (Hennart, 2009). Wearing the mask of homogeneity across firms, in terms of likely impacts of cultural distance can lead to statistically significant results, but what these might imply for actual managerial choice and economic performance, if anything, is unclear.

Mask 4. Finally, the tenth assumption is related to the appropriateness of bundling individual distance measures into aggregate indices that can easily be applied in IB and management studies, whether at the micro or macro-levels. From the perspective of expediency, such indices make perfect sense because they are easy to apply and confer instant legitimacy to the study at hand, especially if they have often been adopted in prior studies as is the case with the K-S index. Unfortunately, this may be at the expense of the research outcomes' validity and reliability, as demonstrated in Håkanson and Ambos' (2010) empirical assessment of psychic distances between 25 countries. The authors found that the K-S index had a particularly weak explanatory power. In contrast, the "fifth" Hofstede dimension, long-term orientation, did add substantial explanatory power, individualism appeared to be important, but inter alia, masculinity was not. Other empirical studies have also identified some Hofstede dimensions, most notably UA and individualism, as more critical to explaining managerial phenomena than other ones (Shenkar, 2001). In more general terms, it would appear that the impact of K-S's index on the quality of cross-cultural research in IB and management may have been mixed.

Having accepted that the unbundling of cultural (or psychic) distance dimensions is important, it should be noted that a rapidly growing stream of applied IB and management research is now focusing on including institutional distance dimensions, in addition to cultural distance ones. Here, it would indeed appear important to include both culture-related and institution-related variables in studies on managerial choice and performance outcomes in international settings, since both are complementary (Xu \& Shenkar, 2002). For 
example, there have been studies analyzing the impact on MNE foreign entry mode decisions of intellectual property rights protection (Delios \& Beamish, 1999; Oxley, 1999), political risk (Brouthers \& Brouthers, 2001) corruption (CuervoCazurra, 2006; Habib \& Zurawicki, 2002), political systems (Dow \& Karunaratna, 2006), sub-national institutional variables (Meyer \& Nguyen, 2005) and regulative, normative and cognitive institutional factors (Yiu \& Makino, 2002).

Meyer (2001) is probably the first researcher who showed the impact of macro-level governance distance between countries on entry mode choice, in the context of emerging economies. Gaur and $\mathrm{Lu}$ (2007) also analyzed the impact of distance in macro-level governance on the survival of MNE foreign subsidiaries. Building on Scott (1995), the authors distinguished between regulative and normative distance and suggested significant effects of both indicators on subsidiary survival. Estrin, Ionascu, and Meyer (2007) found significant effects on entry mode choice of the regulative, normative and cognitive components of institutional distance.

This last approach suggests the almost natural complementarity between cultural and institutional distance dimensions, though it should be recognized that much of the institutional distance literature suffers less than the cultural distance literature from homophily, in that institutional quality is often considered more important than institutional proximity (Globerman \& Shapiro, 2003; Kaufmann, Kraay, \& Mastruzzi, 2003). A relatively recent research stream in the international strategy literature indeed suggests that the foreign regulatory environment may have more of an influence on MNE behavior than previously recognized (Coeurderoy \& Murray, 2008; Henisz, 2000; Kostova \& Zaheer, 1999). In this context, a number of authors have also claimed - at the intersection between institutional distance and institutional quality - that the costs of doing business abroad may be affected significantly by the level of regional integration between the countries involved (Benito, Grøgaard, \& Narula, 2003; Berry, Guillén, \& Zhou, 2010; Hejazi, 2007; Rugman \& Verbeke, 2004).

The mask of bundling a predetermined set of cultural distance parameters into standard indices in applied IB studies is again intuitively appealing, but likely to disguise or ignore much of the full spectrum of parameters that actually matter. This is not merely an empirical study design issue but goes to the heart of conceptualizing cross-cultural studies: what do IB and management scholars actually try to achieve with their work? Is it establishing some statistically significant relationship vs truly understanding managerial choice and economic performance in a cross-cultural and cross-institutional context?

\section{CONCLUSIONS}

We have discussed 10 common assumptions in applied IB and management research on cultural distance dimensions and measures. While substantial advances have been made in the field since cultural dimensions received widespread attention with the publication of Hofstede's (1980) seminal work, our conclusion is not necessarily very encouraging in terms of the state-of-the-art. The scholarly fields of IB and management in general are now populated by a number of "clubs", each of which has very specific views on the inclusion of cultural distance dimensions and measurable proxies thereof in academic studies. For example, many authors and journal reviewers still feel it is entirely appropriate to use K-S type indices, whereas a growing number of others reject this outright as being a vestige of the "dark middle ages" of crosscultural research.

We see four distinct challenges that exist for researchers doing applied work and contemplating the use of K-S type indices: first, addressing possible quality problems with the inputs (e.g., scores for the underlying cultural distance dimensions, as identified in work such as Hofstede's) that are instrumental to calculating index values; second, assessing the relevance of these inputs, which reflect national, societal values rather than managerial perceptions; third, reflecting on the usefulness of a compound index in which each component is given an equal weight, when some components should carry more weight than other ones; fourth, making explicit the assumptions adopted by researchers as to the index's usefulness to help explain managerial choices, practices and economic performance, taking into account that cultural distance is not the same as psychic distance.

The Hofstede-GLOBE debate included in this issue of JIBS has provided substantial intellectual spark, but has not answered the question as to possible complementarities, although the Venaik and Brewer paper has shed some light on this issue in the context of the UA dimension. In addition, the linkages with other approaches, such as the Schwartz paradigm (e.g., Schwartz, 1994), the World 
Values Survey (Inglehart, 1997) and Trompenaars and Hampden-Turner (1997), were not investigated in depth. Many scholars may believe, after reading the various pieces included here, that they should perhaps include both Hofstede-based and GLOBEbased measures in their empirical work as well as alternative indices in order to avoid the wrath of reviewers strongly positioned in one particular camp. But is this the right way forward? We do not think so.

We see the way forward as threefold for IB and management scholars engaged in applied research on the effects of cultural distance. First, scholars should adopt a broad conceptual view of the distance concept, embracing cultural, institutional, economic and spatial components, and include in their empirical studies the various dimensions most likely to affect ex ante the managerial choices or ex post the performance areas being investigated. The goal, however, is not to be exhaustive in terms of including measures for all the distance dimensions and control variables that could possibly be considered, but to set up credible research designs that can actually help explain the managerial phenomena being investigated. ${ }^{5}$ Second, scholars should revisit and challenge their own research frames, especially in terms of how the 10 common assumptions and in particular the four masks included in Table 1, may affect the scholarly credibility and managerial relevance of their empirical work. Authors should at least be explicit on why they made (or were forced to make) some of these assumptions. Third, in our view, the four masks, and within these the unbundling issue, are probably the most critical items that need to be addressed. Perhaps it is correct that some cultural distance dimensions and related scores for distance measures might (1) be affected in only a minor way by (intra-national) spatial characteristics; (2) usually have the same "sign" in terms of the nature of the impact on managerial choices or ease of doing business abroad; (3) have a large, direct impact in an absolute sense on discrete managerial choices or overall performance levels; and (4) have an impact largely independent of other distance components and therefore can simply be "added" to other distance dimensions within the framework of a standard, overall distance measure. However, what we do know is that some cultural distance dimensions and related scores for distance measures actually (1) are affected by intra-national location elements, including the extent of cultural tightness-looseness proposed by Gelfand et al. (2006);
(2) do not have the same type of impact in all situational contexts; (3) may not be directly instrumental to managerial choice and economic performance; and (4) probably do not exert any influence independently of other distance dimensions - and therefore cannot be simply added to scores for other dimensions using a standard, overall distance measure. In these situations, masking individual distance dimensions through the use of simple aggregate indices may actually render a disservice to students trying to understand the impact of distance on managerial choices and economic performance, to scholars attempting to build upon this prior work, and to managers facing real-world distance challenges and looking for guidance from the scholarly IB and management communities.

The way forward to improve the quality of applied IB and management research is for scholars to have an impeccable command of the full (and still growing) arsenal of instruments for measuring distance dimensions and providing distance scores. Such command should then lead to selecting in a judicious rather than expeditious manner the unbundled distance dimensions and related measures, including the cultural, institutional, economic and spatial ones that are most likely to affect the ex ante managerial choices or ex post performances being investigated, while avoiding the obvious endogeneity problems haunting much of the past research. Cross-cultural analysis in IB and management research should also systematically consider competing hypotheses and alternative explanations in terms of the possible impacts of distance dimensions, and not limit itself to simply adopting readily available compound indices as easy tools to determine whether culture does matter to managerial choice and economic performance. ${ }^{6}$

Finally, there is an exciting challenge ahead for scholars engaged in fundamental rather than applied research on how cultural values vary across space and time, and how these should be operationalized and measured. It is time for independent scholars to revisit in a comprehensive fashion the quality of the available arsenal of instruments and parameters in the realm of cultural dimensions, and adopted in applied IB and management research. In other words, the way forward appears to center around two major challenges, namely to determine: First, which - if any - of these tools and parameters really hold up against the quality standards of contemporary scholarly endeavor in terms of validity and reliability? Second, which of 
these measures are most appropriate in light of the research questions and context at hand?

\section{ACKNOWLEDGEMENTS}

We thank Lorraine Eden and three anonymous reviewers for their valuable feedback and suggestions that have greatly improved the paper.

\section{NOTES}

${ }^{1}$ It is worth noting that when the Uppsala School first operationalized the "psychic distance" construct, discussed under Assumption 6, asymmetry was implied (Vahlne \& Wiedersheim-Paul, 1973). However, because the measurements involved only one focal country, this aspect was not elaborated upon; over time, this assumption of asymmetry was distorted to imply symmetry. Several studies found evidence of asymmetry (Brock, Shenkar, Shoham, \& Siscovick, 2008; Dichtl, Koeglmayr, \& Mueller, 1990; Dow, 2000; Ellis, 2007; Håkanson \& Ambos, 2010).

${ }^{2}$ For a detailed description of this index, albeit using inputs from GLOBE, see the paper by Sarala and Vaara in this Special Issue.

${ }^{3}$ In this context, one of the reviewers of this article commented that the $\mathrm{K}-\mathrm{S}$ index is not a good indicator of similarity. The cultural distance between Austria and Japan is 1.5 according to this index, whereas the difference between Austria and Sweden is 4.04.

${ }^{4}$ One reviewer of this article commented that negative stereotypes about culturally proximate nations, especially those in a situation of economic dominance, can also be found in Europe (e.g., Austria

\section{REFERENCES}

Barkema, H. G., Bell, J. H. J., \& Pennings, J. M. 1996. Foreign entry, cultural barriers and learning. Strategic Management Journal, 17: 151-166.

Beckerman, W. 1956. Distance and the pattern of intraEuropean trade. The Review of Economics and Statistics, 38(1): 31-40.

Benito, G. R. G., Grøgaard, B., \& Narula, R. 2003. Environmental influences on MNE subsidiary roles: Economic integration and the Nordic countries. Journal of International Business Studies, 34(5): 443-456.

Berry, H., Guillén, M. F., \& Zhou, N. 2010. An institutional approach to cross-national distance. Journal of International Business Studies, Advance online publication, 1 July; doi: 10.1057/jibs.2010.28

Brock, D. M., Shenkar, O., Shoham, A., \& Siscovick, I. C. 2008. National culture and expatriate deployment. Journal of International Business Studies, 39(8): 1293-1309.

Brouthers, K. D., \& Brouthers, L. E. 2001. Explaining the national cultural distance paradox. Journal of International Business Studies, 32(1): 177-189.

Brown, L., Rugman, A., \& Verbeke, A. 1988. Japanese joint ventures with Western multinationals: Synthesizing the economic and cultural explanations of failure. Journal of Pacific Asian Management, 6(2): 225-242. vs Germany; Canada vs the United States), though this does not necessarily affect IB transactions. Similarly, the country-of-origin literature where animosity (i.e., perceptions of inferior quality) held by consumers, especially those from emerging markets is often associated with products from other emerging markets, suggests that the homophily assumption needs to be challenged (see, Funk, Arthurs, Treviño, \& Joireman, 2009).

${ }^{5}$ In other words, we think that a continued focus on the distance concept, with distance having a variety of potentially negative and positive effects, remains particularly valuable to the field of IB research, because of its role in explaining IB expansion choices, managerial practices, and performance outcomes. However, we advocate the use of cultural distance as an "envelope concept", with its precise content to be determined ex ante in empirical studies, as a function of the research questions to be answered. Here, concepts such as cultural intelligence, cultural complementarity and cultural diversity can be usefully folded into the cultural distance envelope concept.

${ }^{6}$ One reviewer suggested viewing culture as a dependent variable rather than as an independent variable in IB studies. Our view is that this would be one bridge too far, since explaining cultural variation or change does not fall within the domain of IB research. However, we do advocate a rich, evolutionary perspective on the use of proxies for cultural variables, whereby researchers should recognize that IB transactions can indeed alter some aspects of culture over time.
Carr, S. C., Rugimbana, R. O., Walkom, E., \& Bolitho, F. H. 2001. Selecting expatriates in developing areas: "Country-of-origin" effects in Tanzania? International Journal of Intercultural Relations, 25: 441-457.

Coeurderoy, R., \& Murray, G. 2008. Regulatory environments and the location decision: Evidence from the early foreign market entries of new-technology-based firms. Journal of International Business Studies, 39(4): 670-687.

Cuervo-Cazurra, A. 2006. Who cares about corruption? Journal of International Business Studies, 37(6): 807-822.

Delios, A., \& Beamish, P. W. 1999. Ownership strategy of Japanese firms: Transactional, institutional, and experience influences. Strategic Management Journal, 20(10): 915-933.

Dichtl, E., Koeglmayr, H.-G., \& Mueller, S. 1990. International orientation as a precondition for export success. Journal of International Business Studies, 21(1): 23-40.

Dow, D. 2000. A note on psychological distance and export market selection. Journal of International Marketing, 8(1): $51-64$.

Dow, D., \& Karunaratna, A. 2006. Developing a multidimensional instrument to measure psychic distance stimuli. Journal of International Business Studies, 37(5): 578-602.

Dow, D., \& Larimo, J. 2008. Psychic distance, international experience and establishment mode. Paper presented at the 
Academy of International Business Annual Meeting, Milan, July, http://works.bepress.com/douglas_dow/14

Ellis, P. D. 2007. Paths to foreign markets: Does distance to market affect firm internationalisation? International Business Review, 16: 573-593.

Estrin, S., lonascu, D., \& Meyer, K. E. 2007. Formal and informal administrative distance, and international entry strategies, William Davidson Working Paper No. 728.

Fang, T. 2005-2006. From "onion" to "ocean": Paradox and change in national cultures. International Studies of Management and Organization, 35(4): 71-90.

Fletcher, R., \& Fang, T. 2006. Assessing the impact of culture on relationship creation and network formation in emerging Asian markets. European Journal of Marketing, 40(3/4): 430-446.

Funk, C. A., Arthurs, J. D., Treviño, L. J., \& Joireman, J. 2009. Consumer animosity in the global value chain: The effect of international production shifts on willingness to purchase hybrid products. Journal of International Business Studies, 41: 639-651.

Gaur, A. S., \& Lu, J. W. 2007. Ownership strategies and survival of foreign subsidiaries: Impacts of administrative distance and experience. Journal of Management, 33(1): 84-110.

Gelfand, M., Nishii, L., \& Raver, J. 2006. On the nature and importance of cultural tightness-looseness. Journal of Applied Psychology, 91: 1225-1244.

Globerman, S., \& Shapiro, D. 2003. Governance infrastructure and US foreign direct investment. Journal of International Business Studies, 34: 19-39.

Habib, M., \& Zurawicki, L. 2002. Corruption and foreign direct investment. Journal of International Business Studies, 33(2): 291-307.

Håkanson, L., \& Ambos, B. 2010. The antecedents of psychic distance. Journal of International Management, 16(3): 195-210.

Hejazi, W. 2007. Reconsidering the concentration of US MNE activity: Is it global, regional or national? Management International Review, 47(1): 5-27.

Henisz, W. 2000. The institutional environment for multinational investment. Journal of Law, Economics and Organization, 16(2): 334-364.

Hennart, J.-F. 2007. The theoretical rationale for a multinationality performance relationship. Management International Review, 47(3): 423-452.

Hennart, J.-F. 2009. Down with MNE-centric theories! Market entry and expansion as the bundling of MNE and local assets. Journal of International Business Studies, 40: 1432-1452.

Heuer, M., Cummings, J. L., \& Hutabarat, W. 1999. Cultural stability or change among managers in Indonesia? Journal of International Business Studies, 30: 599-610.

Hofstede, G. 1980. Culture's consequences: International differences in work-related values. Beverly Hills, CA: Sage.

Hofstede, G. 1994. The business of international business is culture. International Business Review, 3(1): 1-14.

Hofstede, G. 2006. What did GLOBE really measure? Researchers' minds versus respondents' minds. Journal of International Business Studies, 37(6): 882-896.

House, R. J., Hanges, P. J., Javidan, M., Dorfman, P. W., \& Gupta, V. (Eds) 2004. Culture, leadership and organizations: The GLOBE study of 62 societies. Thousand Oaks, CA: Sage.

Hutzschenreuter, T. \& Voll, 1. 2008. Performance effects of "added cultural distance" in the path of international expansion: The case of German multinational enterprises. Journal of International Business Studies, 39: 53-70.

Hutzschenreuter, T., Voll, J., \& Verbeke, A. 2010. The impact of added cultural distance and cultural diversity on international expansion patterns: A Penrosean perspective. Journal of Management Studies, doi: 10.1111/j.1467-6486.2010.00966.x.

Ibarra, H. 1993. Personal networks of women and minorities in management: A conceptual framework. Academy of Management Review, 18(1): 56-87.
Inglehart, R. 1997. Modernization and postmodernization: Cultural, economic, and political change in 43 societies. Princeton, NJ: Princeton University Press.

Inglehart, R. and Associates (Undated). World values surveys. http://www.worldvaluessurvey.org/.

Johanson, J., \& Vahlne, J.-E. 1977. The internationalization process of the firm - A model of knowledge development and increasing foreign market commitments. Journal of International Business Studies, 8(1): 23-32.

Johanson, J., \& Vahlne, J.-E. 2009. The Uppsala internationalization process model revisited - From liability of foreignness to liability of outsidership. Journal of International Business Studies, 40(9): 1411-1431.

lohnston, W. B. 1991. Global workforce 2000: The new world labor market. Harvard Business Review, 69(2): 115-127.

Kaufmann, D., Kraay, A., \& Mastruzzi, M. 2003. Governance matters III: Governance indicators for 1996-2002, Working Paper, World Bank Policy Research Department.

Kogut, B., \& Singh, H. 1988. The effect of national culture on the choice of entry mode. Journal of International Business Studies, 19(3): 411-432.

Kostova, T., \& Zaheer, S. 1999. Organizational legitimacy under conditions of complexity: The case of the multinational enterprise. Academy of Management Review, 24(1): 64-81.

Lazarsfeld, P., \& Merton, R. 1954. Friendship as a social process: A substantive and methodological analysis. In M. Berger (Ed.) Freedom and control in modern society: 18-66. New York: Van Norstand.

Leung, K., Bhagat, R. S., Buchan, N. R., Erez, M., \& Gibson, C. B. 2005. Culture and international business: Recent advances and their implications for future research. Journal of International Business Studies, 36(4): 357-378.

Mamman, A. 1995. Expatriate adjustment: Dealing with hosts attitudes in a foreign assignment. Journal of Transnational Management Development, 1: 49-70.

McSweeney, B. 2002. Hofstede's model of national cultural differences and their consequences: A triumph of faith $-A$ failure of analysis. Human Relations, 55: 89-118.

Meyer, K. E. 2001. Institutions, transaction costs, and entry mode choice in Eastern Europe. Journal of International Business Studies, 32(2): 357-367.

Meyer, K. E., \& Nguyen, H. V. 2005. Foreign investment strategies and sub-national institutions in emerging markets: Evidence from Vietnam. Journal of Management Studies, 42(1): 63-92.

Miller, S., Thomas, D., Eden, L., \& Hitt, M. 2008. Knee deep in the big muddy: The survival of emerging market firms in developed markets. Management International Review, 48(6): 645-666.

Naylor, L. L. 1996. Culture and change: An introduction. Portsmouth, NH: Greenwood.

O'Grady, S., \& Lane, H. W. 1996. The psychic distance paradox. Journal of International Business Studies, 27(2): 309-333.

Oxley, J. 1999. Institutional environment and the mechanisms of governance: The impact of intellectual property protection on the structure of inter-firm alliances. Journal of Economic Behavior and Organization, 38(3): 283-309.

Oyserman, D., Coon, H. M., \& Kemmelmeier, M. 2002. Rethinking individualism and collectivism: Evaluation of theoretical assumptions and meta-analyses. Psychological Bulletin, 128: 3-72.

Peterson, M. F. 2004. Review of culture, leadership and organizations: The GLOBE study of 62 societies by House R.J., Hanges P.J., Javidan M., Dorfman P.W. \& Gupta V. 2004. Administrative Science Quarterly, 49(4): 641-647.

Ralston, D. A. 2008. The crossvergence perspective: Reflections and projections. Journal of International Business Studies, 39(1): 27-40.

Ralston, D. A., Egri, C. P., Stewart, S., Terpstra, R. H., \& Yu, K. C. 1999. Doing business in the 21 st century with the new 
generation of Chinese managers: A study of generational shifts in work values in China. Journal of International Business Studies, 30(2): 415-428.

Rugman, A. 1981. Inside the multinationals: The economics of internal markets. New York: Columbia University Press.

Rugman, A., \& Verbeke, A. 2001. Subsidiary-specific advantages in multinational enterprises. Strategic Management Journal, 22: 237-250.

Rugman, A., \& Verbeke, A. 2004. A perspective on regional and global strategies of multinational enterprises. Journal of International Business Studies, 35: 3-18.

Rugman, A., \& Verbeke, A. 2005. Towards a theory of regional multinationals: A transaction cost economics approach. Management International Review, 45(Special Issue): 5-17.

Rugman, A., \& Verbeke, A. 2008. The theory and practice of regional strategy: A response to Osegowitsch and Sammartino. Journal of International Business Studies, 39(2): 326-332.

Saxenian, A. 2002. Brain circulation: How high-skill immigration makes everyone better off. The Brookings Review, 20(1): 28-31.

Schwartz, S. H. 1994. Beyond individualism/collectivism: New cultural dimensions of values. Thousand Oaks, CA: Sage.

Scott, W. R. 1995. Institutions and organizations. Thousand Oaks, CA: Sage.

Selmer, J., Chiu, R. K., \& Shenkar, O. 2007. Cultural distance asymmetry in expatriate adjustment. Cross Cultural Management: An International Journal, 14: 150-160.

Shenkar, O. 2001. Cultural distance revisited: Towards a more rigorous conceptualization and measurement of cultural differences. Journal of International Business Studies, 32(3): 519-535.

Stahl, G. K., Miller, E. L., \& Tung, R. L. 2002. Toward the boundaryless career: A closer look at the expatriate career concept and the perceived implications of an international assignment. Journal of World Business, 37(3): 216-227.

Tihanyi, L., Griffith, D. A., \& Russell, C. J. 2005. The effect of cultural distance on entry mode choice, international diversification, and MNE performance: A meta-analysis. Journal of International Business Studies, 36(3): 270-283.

Trompenaars, F., \& Hampden-Turner, C. 1997. Riding the waves of culture: Understanding cultural diversity in business (2nd ed.) London: Nicholas Brealey.

Tung, R. L. 1998. American expatriates abroad: From neophytes to cosmopolitans. Journal of World Business, 33(2): 125-144.

Tung, R. L. 2007. The human resource challenge to outward foreign direct investment aspirations from emerging economies: The case of China. International Journal of Human Resource Management, 18(5): 868-889.

Tung, R. L. 2008a. The cross-cultural research imperative: The need to balance cross-national and intra-national diversity. Journal of International Business Studies, 39(1): 41-46.

Tung, R. L. 2008b. Human capital or talent flows: Implications for future directions in research on Asia Pacific. Asia Pacific Business Review, 14(4): 469-472.

Tung, R. L., \& Baumann, C. 2009. Comparing the attitudes toward money, material possessions and savings of overseas Chinese vis-à-vis Chinese in China: Convergence, divergence or cross-vergence, vis-à-vis "one size fits all" human resource management policies and practices. International Journal of Human Resource Management, 20(11): 2382-2401.

Tung, R. L., \& Chung, H. F. L. 2010. Diaspora and trade facilitation: The case of ethnic Chinese in Australia. Asia Pacific Journal of Management, 27(3): 371-392.

Tung, R. L., Worm, V., \& Fang, T. 2008. Sino-Western business negotiations revisited - 30 years after China's Open Door Policy. Organizational Dynamics, 37(1): 60-74.
Vahlne, J. E \& Wiedersheim-Paul, F. 1973. Economic distance: Model and empirical investigation. In E. Hornell, J.-E. Vahlne \& F. Wiedersheim-Paul (Eds) Export and foreign establishments: 81-159. Uppsala: University of Uppsala, (book and chapter title are English translations of the original publication).

Verbeke, A. 2009. International business strategy. Cambridge: Cambridge University Press.

Verbeke, A. 2010. International acquisition success: Social community and dominant logic dimensions. Journal of International Business Studies, 41(1): 38-46.

Verbeke, A., \& Brugman, P. 2009. Triple-testing the quality of multinationality-performance research: An internalization theory perspective. International Business Review, 18: 265-275.

Verbeke, A., \& Kenworthy, T. 2008. Multidivisional versus metanational governance of the multinational enterprise. Journal of International Business Studies, 39(2): 940-956.

Verbeke, A., Li, L., \& Goerzen, A. 2009. Toward more effective research on the multinationality-performance relationship. Management International Review, 49: 149-162.

Von Glinow, M. A., Shapiro, D. L., \& Brett, J. M. 2004. Can we talk, and should we? Managing emotional conflict in multicultural teams. Academy of Management Review, 29(4): 578-592.

Xu, D., \& Shenkar, O. 2002. Institutional distance and the multinational enterprise. Academy of Management Review, 27: 608-618.

Yiu, D., \& Makino, S. 2002. The choice between joint venture and wholly owned subsidiary: An institutional perspective. Organization Science, 13(6): 667-683.

\section{ABOUT THE AUTHORS}

Rosalie L Tung is a chaired Professor of International Business at Simon Fraser University. She is a past President of the Academy of Management. Her research interests are in strategic international human resource management and comparative management. She was born in China, received her $\mathrm{PhD}$ from the University of British Columbia, and is a dual citizen of the US and Canada. She can be reached at tung@sfu.ca.

Alain Verbeke holds the McCaig Chair in Management and is Head of the Strategy and Global Management Area at the University of Calgary (Canada). He is associated with CIBAM, University of Cambridge (UK), the Rotterdam School of Management (NL) and the University of Brussels (VUB, Belgium), where he was previously the Director of the Solvay Business School MBA program. He has extensive practical experience in multinational strategic planning and MNE headquarters-subsidiary relationships. Alain is a Belgian citizen, and can be reached at averbeke @ucalgary.ca. 